\title{
A Novel Prognostic Score based on Serum Alpha-Fetoprotein, Number of Nodules, and MYC Gene Status Predicts Prognosis of Patients after Liver Resection for Hepatocellular Carcinoma
}

Andrea Ruzzenente ${ }^{1}$, Fabio Bagante ${ }^{1}$, Marco Sandri BS², Corrado Pedrazzani', Matteo Brunelli³ ${ }^{3}$ Tommaso Campagnaro', Simone Conci ${ }^{1}$, Paola Capelli ${ }^{3}$, Alfredo Guglielmi ${ }^{1}$, Aldo Scarpa ${ }^{3}$ and Calogero lacono ${ }^{1 *}$

${ }^{1}$ Department of Surgery and Oncology, Division of General and Hepatobiliary Surgery, School of Medicine, University of Verona, University Hospital "GB Rossi”, Verona, Italy

${ }^{2}$ Center for Research into "Data, Methods and Systems", University of Brescia, Brescia, Italy

${ }^{3} A R C-N e t$ Research Center and Department of Pathology and Diagnostics, University of Verona Medical School, University Hospital "GB Rossi", Verona, Italy

\begin{abstract}
Recurrence after liver surgery for hepatocellular carcinoma (HCC) remains the major dismal event affecting patient's overall survival (OS). Several studies on gene signature showed an association between MYC deregulation and poor prognosis. We aimed to analyze prognostic factors, including MYC status, for disease free survival (DFS) and OS, as well as to develop a new prognostic model for HCC able to predict the patient's prognosis.

Methods: Sixty-three patients who underwent liver resection for HCC from January 2006 to December 2009 in a single division of the Department of Surgery at the University of Verona were included into this study. Predictors of DFS and OS were identified using univariate and multivariate survival analysis. The prognostic ability of our model was compared using Harrell's c-index to current clinical staging systems (AJCC/TNM $7^{\text {th }}$ ed., BCLC and CLIP).

Results: Predictors of DFS, in both univariate and multivariable analysis were number of HCC, serum AFP, and MYC status; these variables were included in a nomogram to predict DFS. Patients were classified into two groups (high- and low-risk group) according to their predicted 12-month risk of recurrence. Patients in low-risk group showed a 36 -month DFS of $43 \%$ compared to $0 \%$ for high-risk group. Furthermore, patients in low-risk group presented a 36 -month OS of $70 \%$ compared to $15 \%$ for high-risk group. Our model was included in AJCC/TNM $7^{\text {th }}$ ed., BCLC and CLIP staging systems. When reclassified with our model, CLIP presented the highest predictive ability (c-index $=73 \%$ ) compared to the others staging-systems.
\end{abstract}

Conclusions: We developed a prognostic model for DFS after hepatectomy for HCC, based on MYC gene status and clinical features (number of nodules and AFP serum level). Our new prognostic model could have important clinical applications in selecting those patients who might have major benefits from surgical resection.

Keywords: HCC; Liver surgery; MYC; Gene amplification; FISH; Staging system

Abbreviations: BCLC: Barcelona-Clinic Liver Cancer; CLIP: Cancer of the Liver Italian Program; TNM: tumor, Node and Metastasis; AFP: Alpha - fetoprotein

\section{Introduction}

Hepatocellular carcinoma (HCC) is the fifth most frequent cancer worldwide and the third most common cause of cancer mortality $[1,2]$. Currently, both the American Association for the Study of Liver Diseases (AASLD) and The European Association for the Study of the Liver (EASL) propose the Barcelona-Clinic Liver Cancer (BCLC) as clinical staging system of HCC $[3,4]$. Moreover, in clinical practice, the AJCC/TNM (7th edition) staging system [5] and the Cancer of the Liver Italian Program (CLIP) classifications [6] are also commonly used. Although these staging systems have been proposed for HCC, their discriminatory abilities remain a matter of debate $[7,8]$.

Prevention and effective management of recurrence are the most important issues for improving overall survival (OS) after hepatectomy for HCC and, for this reason, researchers have investigated several clinical and pathological prognostic factors to identify patients at high risk of recurrence $[9,10]$. Currently, none of these factors can accurately estimate the risk of recurrence in patients undergoing liver resection for HCC.

Recently, the efforts to identify prognostic factors for disease-free survival (DFS) and OS have focused on the genetic and molecular characteristics of HCC. The MYC proto-oncogene is one of the most frequently activated oncogenes in tumor cells and is estimated to be involved in up to $20 \%$ of all human cancers [11]. In HCC, MYC overexpression has been identified in about $70 \%$ of viral and alcoholrelated tumors [12], and several animal models pointed out that MYC is a key gene regulator involved in hepatocarcinogenesis [13]. MYC is a transcription factor that can influence approximately $15 \%$ of genes involved in metabolism, protein biosynthesis, cell cycle regulation, cell adhesion and cytoskeleton synthesis [14-16]. Moreover, MYC appears to affect angiogenesis, although it is unclear whether MYC directly regulates VEGF [17]

*Corresponding author: Calogero lacono, Department of Surgery and Oncology, Division of General and Hepatobiliary Surgery, School of Medicine, University of Verona, University Hospital "GB Rossi", Italy, Tel: +39 045 8124412; Fax: +39 045 8027426; E-mail: Calogero.lacono@univr.it

Received April 04, 2016; Accepted May 10, 2016; Published May 18, 2016

Citation: Ruzzenente A, Bagante F, Sandri BSM, Pedrazzani C, Brunelli M, et al (2016) Risk A Novel Prognostic Score based on Serum Alpha-Fetoprotein, Number of Nodules, and MYC Gene Status Predicts Prognosis of Patients after Live Resection for Hepatocellular Carcinoma. J Integr Oncol 5: 168. doi:10.4172/23296771.1000168

Copyright: (c) 2016 Ruzzenente A, et al. This is an open-access article distributed under the terms of the Creative Commons Attribution License, which permits unrestricted use, distribution, and reproduction in any medium, provided the original author and source are credited. 
Citation: Ruzzenente A, Bagante F, Sandri BSM, Pedrazzani C, Brunelli M, et al. (2016) Risk A Novel Prognostic Score based on Serum AlphaFetoprotein, Number of Nodules, and MYC Gene Status Predicts Prognosis of Patients after Liver Resection for Hepatocellular Carcinoma. J Integr Oncol 5: 168. doi:10.4172/2329-6771.1000168

MYC can be overexpressed as a result of two types of alterations: gene amplification involving the specific locus region 8q24 (i.e., an increase in the number of copies of a specific gene with respect to the whole chromosome) or polysomy (i.e., gains of the entire chromosome 8). There is increasing amount of evidence demonstrating that these different mechanisms of dysregulation leading to MYC overexpression may impact patient's prognosis [18-21]. Interestingly, MYC inhibitors and drugs targeting molecules involved in MYC pathways are being tested in different experimental and clinical conditions [22,23]. We demonstrated that the copy number status of MYC analyzed through fluorescence in situ hybridization (FISH) is an important prognostic factor in terms of DFS and OS for HCC [24].

Although different genetic signatures have been proposed for HCC [25], current clinical staging system do not include any molecular features of tumors [26,27]. We believe that a more detailed characterization of HCC based on gene status could improve the treatment allocation and the discriminatory ability of the common staging systems.

We aimed (1) to analyze clinical and pathological predictors of DFS and (2) of OS as well as (3) to develop a new prognostic model for HCC and (4) to compare the performances of our model to those of the common clinical staging systems (AJCC/TNM $7^{\text {th }}$ ed., BCLC and CLIP).

\section{Materials and Methods}

Sixty-three patients who underwent liver resection from January 2006 to December 2009 in a single division of the Department of Surgery at the University of Verona were included in this study.

Non-invasive diagnosis of HCC was made according to the EASL consensus conference criteria [3]. The diagnosis of HCC was based on imaging techniques obtained by 4-phase multidetector CT scan or dynamic contrast-enhanced MRI according to the typical hallmark of HCC (hypervascular in the arterial phase with washout in the portal venous or delayed phases). While one imaging technique was required for nodules beyond $1 \mathrm{~cm}$ in diameter a more conservative approach with 2 techniques was recommended in suboptimal settings; invasive methods was performed in patients with uncertain diagnosis by fineneedle biopsy.

The liver function was assessed preoperatively by laboratory parameters (bilirubin, AST, ALT, GGT, albumin, prothrombin time, creatinine level, serum sodium), Child-Pugh scoring system and indocyanine green clearance retention rate at 15 minutes (ICG R15). Portal hypertension was evaluated by assessment of esophageal varices, platelet count and splenomegaly.

Preoperative imaging included chest radiography, liver ultrasonography and abdominal-CT and/or abdominal MRI.

The decision to treat patients with surgical resection was determined in a multidisciplinary meeting (including gastroenterologists, oncologists and radiologists - Verona Multidisciplinary Hepatobiliary Oncological Group) according to EASL guidelines [4]. Selected cases with large, multinodular HCC ( $>3$ nodules) or with ChildPugh B7 cirrhosis or with portal hypertension were discussed in the multidisciplinary meeting to evaluate the surgical resectability. During surgery, intraoperative ultrasonography was routinely used to confirm the preoperative diagnosis, to evaluate the relationship between the tumor and blood vessels and to evaluate the presence of additional tumors. The extent of resection was defined according to the Brisbane classification [28]. Type of resection included wedge resections, segmentectomies, bisegmentectomies, and major resections (more than or equal to three segments). Anatomical or nonanatomical liver resections were performed according to the extent and location of the tumor and hepatic function. Operative details were collected, such as type of liver resection and associated resections, presence and type of clamping, intraoperative blood loss and blood transfusion requirement. Clinical follow-up after surgery included using serum alpha-fetoprotein serum levels (AFP) dosage and ultrasonography/ CT every 6 months, suspected recurrences were confirmed with CT or MRI.

Pathologic data included examination size of the largest tumor nodule and the number of satellite nodules, macrovascular and microvascular invasion, necrosis, status of extra-tumoral parenchyma.

Grade of differentiation was based on Edmondson-Steiner classification [29].

FISH to assess MYC gene copy number was performed as previously described [24]. MYC status was classified according to the ratio between the overall fluorescent MYC copy number signals and the centromeric control probe (CEP8) copy number: normal disomic status (2 MYC signals and 2 centromeric probe signals in $>90 \%$ of nuclei), polysomic status ( $>2$ MYC signals with $>2$ CEP8 signals in more than $10 \%$ of cell nuclei) and amplified status ( $>3$ MYC signals in $>10 \%$ of nuclei with 2 CEP8 signals in more than $10 \%$ of cell nuclei). The MYC evaluation was performed in 5 different parts of the same tumor and in different tumors (for multinodular HCC) in order to evaluate the heterogeneity of the tumor. The percentages of cells with MYC status were evaluated in comparison to extralesional parenchyma. Experts in this field (liver, breast and renal cancer) performed the evaluation of MYC status (MB, AS and PC).

The Strengthening the Reporting of Observational Studies in Epidemiology (STROBE) recommendations were used as a reporting guideline to ensure a clear and complete report of the study's design, conduct, and findings [30].

\section{Statistical analysis}

The distributions of categorical and numerical variables between independent groups were compared using Fisher's exact test and a Mann-Whitney U test, respectively. OS was defined as the time interval between treatment and either death from any cause or last follow-up. DFS was calculated from the date of treatment to either the date of the first radiological evidence of recurrence or last follow-up. Patients' clinical data and, pathological and molecular features of HCC were investigated to identify important risk factors in term of DFS and OS. Survival curves were estimated using the Kaplan-Meier method, and differences between survival curves were tested using the exact log-rank test. Significant variables identified in the univariate analysis were subsequently used in the multivariable Cox proportional model for the development of a predictive score. The existence of statistically significant interaction terms was tested using the likelihood-ratio test. A p-value $<0.05$ was considered statistically significant.

\section{Clinical and molecular model}

First, we developed a prognostic clinical tool including variables selected in the multivariable Cox regression model. A commonly accepted cut-off for early recurrence is not available in the literature [31]. We selected a 12-month threshold to underline the importance of HCC with aggressive progression [32]. A prognostic score for the risk of recurrence before or at 12 months after liver resection was estimated 
Citation: Ruzzenente A, Bagante F, Sandri BSM, Pedrazzani C, Brunelli M, et al. (2016) Risk A Novel Prognostic Score based on Serum AlphaFetoprotein, Number of Nodules, and MYC Gene Status Predicts Prognosis of Patients after Liver Resection for Hepatocellular Carcinoma. J Integr Oncol 5: 168. doi:10.4172/2329-6771.1000168

using the above model. To make this procedure more easily accessible in clinical practice, we calculated the score using a nomogram. Partial scores were first computed for every prognostic factor, and then, they were summed to find the total predictive score for the risk of early recurrence. Finally, the total score was dichotomized (cut-off level $=95$ points), and patients were classified as either low or high risk regarding the development of early recurrence (risk $\leq 50 \%$ and $>50 \%$, respectively).

Regarding the discriminatory abilities of AJCC/TNM $7^{\text {th }}$ ed., BCLC and CLIP were assessed by estimating a Cox model for OS (with the score as a unique covariate) and by measuring Somers' Dxy rank correlation and Harrell's c-index. The latter index is an extension of the receiver operating characteristic (ROC) curve area to survival analysis and is measured on a scale ranging from 0.5 (no better than chance) to 1 (perfect prediction) [33].

A bootstrap (with 5000 repetitions) resampling validation was computed to avoid an optimistic estimation of the c-index.

Statistical analyses and a graphical representation of the results were carried out using the R software for statistical computing, v. 3.0.2 [34], with the following packages: survival [35], rms [36], and coin [37] (Figure 1).

\section{Results}

Sixty-three patients included in the study had a median followup time of 24.3 months (IQR=16.9-33.6). During follow-up, 20 (31.7\%) patients died, and $36(57.1 \%)$ patients had a recurrence. The characteristics of the patients and the univariate and multivariate analyses for DFS are reported in Table 1. In both univariate and multivariable survival analyses the variables significantly related to DFS were: the number of nodules, the serum AFP level and the MYC status (Table 1).

\section{Clinical and molecular model for DFS}

Among the 36 patients who had a recurrence, 23 (63.9\%) patients recurred within 12 months. A model to predict DFS was developed using a Cox multivariate model and included number of HCC (from one nodule to four), serum AFP levels $(\mathrm{ng} / \mathrm{mL}$ ) and MYC status. Figure 2a shows a graphical representation of our model was to simplify its clinical use. The probability of early recurrence was showed on a 2-dimensional plot, stratified by MYC status (disomic, polysomic or amplified), with the number of nodules on the $\mathrm{x}$-axis and the serum AFP levels on the y-axis. A nomogram (Figure $2 b$ ) was used to predict the recurrent disease within 12 months: a total score can be calculated summing the partial scores of the three prognostic factors (AFP levels, number of nodules and MYC status). Two groups (high and low risk) of patients were identified using the predictions of our nomogram with a cut-off value of 95 points corresponding to a risk of recurrence at 12 months $>50 \%$. According to our classification, 51 (80.9\%) patients were in the low risk group, which demonstrated a 36-month DFS of $43.4 \%$ (95\% CI $=29.4 \%-64.0 \%)$ while $12(19.1 \%)$ patients were in the high risk group that showed a DFS at 36 months of $0 \%(p<0.001)$, (Figure $2 c)$.

\section{Clinical and molecular prognostic model and staging systems for overall survival (OS)}

The variables related to OS in the univariate analysis resulted number of nodule, serum AFP level, albumin, PT, MYC status, and the risk of recurrence calculated using our predictive model (Table 2). In the multivariable analysis, the risk of recurrence calculated using our predictive model resulted the only variable significantly related to
OS with a HR of 6.82 (95\%CI, 2.72-17.1; Table 2). Despite only $19.1 \%$ $(n=12)$ of patients were in the high risk class, two third $(75.0 \%, n=9)$ of them died with an OS at 36 months of $15.0 \%$ (95\%CI $=2.8 \%-78.8 \%)$.

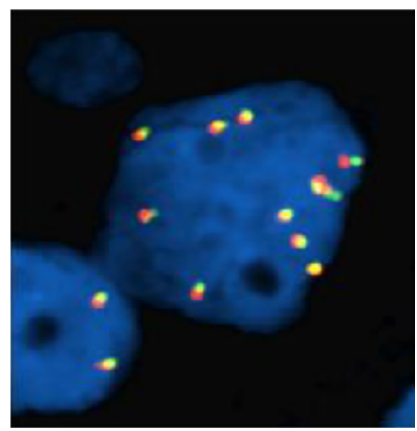

Figure 1: FISH analysis on routinely available paraffin block: c-myc gene amplification in a neoplastic nucleus from hepatocellular carcinoma and normal nuclei as controls. HCC were classified into three categories according the number of MYC fluorescent signals (red) and the number of centromeric control probe (yellow). HCC demonstrated a normal disomic status when observing 2 MYC signals (red) and 2 centromeric probe signals (yellow), a polysomic status if we found $>2$ MYC signals (red) with $>2$ centromeric probe signals (yellow), and amplified status for $>3$ MYC signals (red) in with 2 centromeric probe signals (yellow).

\begin{tabular}{|c|c|c|c|c|c|}
\hline & N (\%) & $\begin{array}{c}\text { DFS }(95 \% \mathrm{Cl}) \text { at } 36 \\
\text { months }\end{array}$ & $\mathbf{p}^{\mathbf{a}}$ & $\begin{array}{c}\text { HR } \underset{\text { Cl) }}{(95 \%} \\
\text { (I) }\end{array}$ & $\mathbf{p}^{\mathbf{b}}$ \\
\hline $\begin{array}{l}\text { Gender } \\
\text { M } \\
\mathrm{F}\end{array}$ & $\begin{array}{l}48(76.2 \%) \\
15(23.8 \%)\end{array}$ & $\begin{array}{l}65.5 \%(40.8 \%-90.1 \%) \\
41.0 \%(25.7 \%-56.3 \%)\end{array}$ & 0.080 & & \\
\hline $\begin{array}{l}\text { Age } \\
\leq 70 \\
>70\end{array}$ & $\begin{array}{l}35(55.6 \%) \\
28(44.5 \%)\end{array}$ & $\begin{array}{c}25.7 \%(7.8 \%-43.5 \%) \\
11.6 \%(24.1 \%-69.5 \%)\end{array}$ & 0.102 & & \\
\hline $\begin{array}{l}\text { Nodule } \\
\text { Single } \\
\text { Multifocal }\end{array}$ & $\begin{array}{l}43(68.3 \%) \\
20(31.7 \%)\end{array}$ & $\begin{array}{c}43.8 \%(25.9 \%-61.6 \%) \\
12.9 \%(0.0 \%-33.7 \%)\end{array}$ & 0.003 & $\begin{array}{c}1.52(1.09 \\
-2.13)\end{array}$ & 0.013 \\
\hline $\begin{array}{l}\text { Size } \\
\leq 3 \mathrm{~cm} \\
>3 \mathrm{~cm}\end{array}$ & $\begin{array}{l}19(30.2 \%) \\
44(69.8 \%)\end{array}$ & $\begin{array}{l}49.9 \%(24.4 \%-75.4 \%) \\
29.7 \%(13.0 \%-46.4 \%)\end{array}$ & 0.330 & & \\
\hline $\begin{array}{l}\text { AFP } \\
\leq 400 \mathrm{ng} / \mathrm{mL} \\
>400 \mathrm{ng} / \mathrm{mL}\end{array}$ & $\begin{array}{l}51(81.0 \%) \\
12(19.0 \%)\end{array}$ & $\begin{array}{c}38.9 \%(23.0 \%-54.8 \%) \\
27.3 \%(1.1 \%-53.5 \%)\end{array}$ & 0.010 & $\begin{array}{c}1.36(1.14 \\
-1.63)\end{array}$ & $<0.001$ \\
\hline $\begin{array}{l}\text { Albumin } \\
\leq 35 \mathrm{~g} / \mathrm{L} \\
>35 \mathrm{~g} / \mathrm{L}\end{array}$ & $\begin{array}{c}5(12.7 \%) \\
58(87.3 \%)\end{array}$ & $\begin{array}{c}37.5 \%(0.0 \%-93.5 \%) \\
35.6 \%(20.7 \%-50.5 \%)\end{array}$ & 0.722 & & \\
\hline $\begin{array}{l}\mathrm{PT} \\
\leq 1.1 \mathrm{INR} \\
>1.1 \mathrm{INR}\end{array}$ & $\begin{array}{l}43(68.3 \%) \\
20(31.7 \%)\end{array}$ & $\begin{array}{c}39.4 \%(23.5 \%-55.3 \%) \\
30 \%(0.0 \%-60.6 \%)\end{array}$ & 0.583 & & \\
\hline $\begin{array}{l}\text { Bilirubin } \\
\leq 2 \mathrm{mg} / \mathrm{mL} \\
>2 \mathrm{mg} / \mathrm{mL}\end{array}$ & $\begin{array}{c}59(93.7 \%) \\
4(6.3 \%)\end{array}$ & $\begin{array}{c}36.9 \%(21.8 \%-51.9 \%) \\
0.0 \% \text { (NA) }\end{array}$ & 0.550 & & \\
\hline $\begin{array}{l}\text { Platelets } \\
\leq 150000 / \mathrm{mm}^{3} \\
>150000 / \mathrm{mm}^{3}\end{array}$ & $\begin{array}{l}22(34.9 \%) \\
41(65.1 \%)\end{array}$ & $\begin{array}{l}38.1 \%(14.4 \%-61.8 \%) \\
32.9 \%(14.5 \%-51.3 \%)\end{array}$ & 0.590 & & \\
\hline $\begin{array}{l}\text { MYC status } \\
\text { Disomic } \\
\text { Polysomic } \\
\text { Amplified }\end{array}$ & $\begin{array}{l}17(26.9 \%) \\
34(53.9 \%) \\
12(19.2 \%)\end{array}$ & $\begin{array}{c}63.8 \%(38.1 \%-89.5 \%) \\
25.2(5.9 \%-44.4 \%) \\
15.0 \%(0.0 \%-40.1 \%)\end{array}$ & 0.020 & $\begin{array}{c}\text { reference } \\
3.29(1.12 \\
-9.73) \\
7.15(2.19 \\
-23.28)\end{array}$ & $\begin{array}{l}0.031 \\
0.001\end{array}$ \\
\hline
\end{tabular}

a $p$-values were obtained using the log-rank test for Kaplan-Meier survival curves. ${ }^{\mathrm{b}} \mathrm{p}$-values were obtained using the multivariate Cox proportional hazard regression model.

Table 1: Baseline characteristics, univariate and multivariate analysis for DFS of 63 patients with HCC. 
Citation: Ruzzenente A, Bagante F, Sandri BSM, Pedrazzani C, Brunelli M, et al. (2016) Risk A Novel Prognostic Score based on Serum AlphaFetoprotein, Number of Nodules, and MYC Gene Status Predicts Prognosis of Patients after Liver Resection for Hepatocellular Carcinoma. J Integr Oncol 5: 168. doi:10.4172/2329-6771.1000168

Page 4 of 9
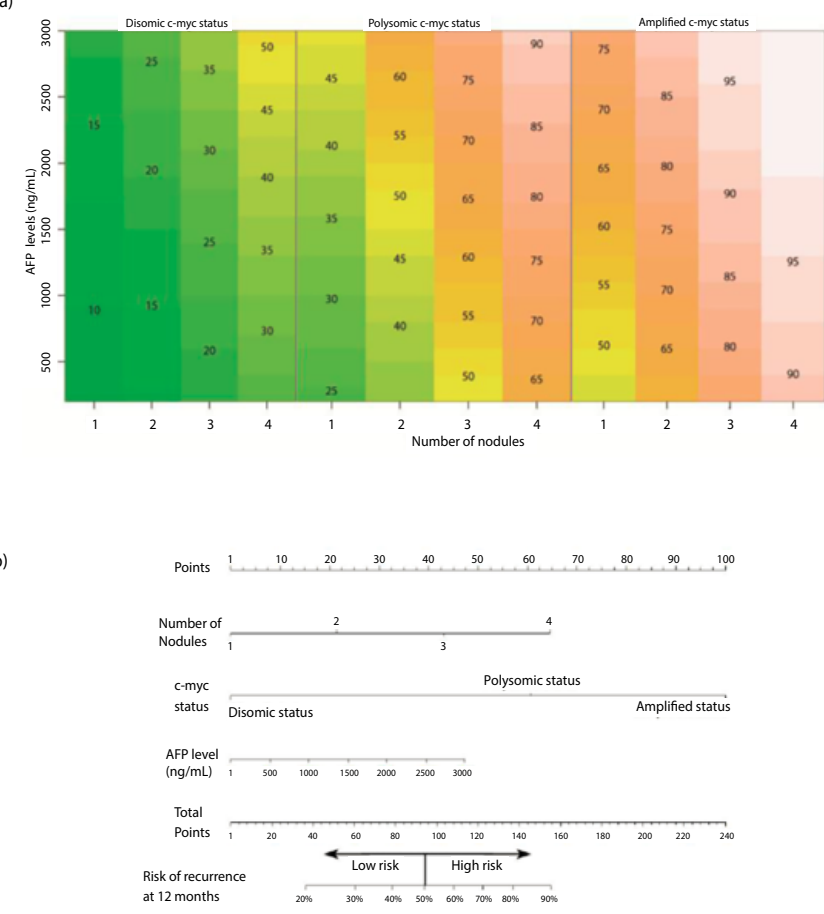

c)

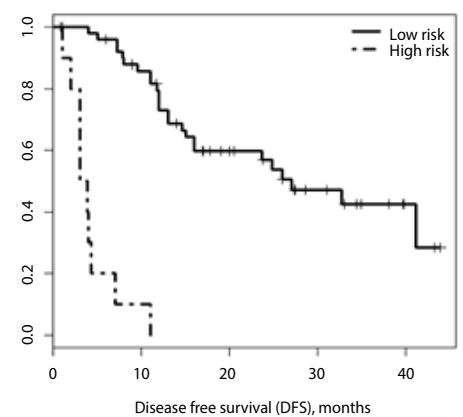

\begin{tabular}{l|rrrrc} 
No. at risk & 0 & 10 & 20 & 30 & 40 \\
\hline Low Risk & 51 & 42 & 29 & 15 & 10 \\
High Risk & 12 & 2 & - & - & - \\
\hline
\end{tabular}

Figure 2: Our novel clinical and molecular model: (a) graphical representation of risk of recurrence before or equal to 12 months stratified by c-myc status (disomic, polysomic and amplified), with number of nodules at $x$-axis and serum AFP levels at $y$-axis. (b) Nomogram, the sum of partial scores gives the total point score to predict the risk of recurrence before or equal to 12 months. (c) Disease free survival curves estimated by Kaplan-Meier method stratified by our classification in High Risk $(>50 \%)$ and Low Risk $(\leq 50 \%)$ of recurrence.

Conversely, $80.9 \%(n=51)$ of patients were in the low risk class, which reached an OS at 36 months of $70.0 \%(95 \% \mathrm{CI}=54.8 \%-89.6 \%$; $<<0.001$; Table 3 and Figure 3).

\section{Staging system subgroup analysis}

To investigate the role of our clinical and molecular model to predict OS, patients were preliminarily staged according to the clinical staging systems (BCLC, CLIP and $\mathrm{TNM}^{7 \text { th }}$ ), as reported in Table 3 and Figure 3. Specifically, $46(73.1 \%)$ patients were classified as BCLC 0 -A with a 36 -month OS of $67.4 \%(95 \% \mathrm{CI}=51.1 \%-89.1 \%)$, while 17 (26.9\%) patients were in BCLC B with a 36-month OS of $37.2 \%$
(95\% CI $=18.2 \%-75.8 \% ; \mathrm{p}=0.01)$. According to the CLIP classification, $36(57.1 \%)$ patients were in stage 0 and showed a 36 -month OS of $71.6 \%$ (95\%CI $=54.6 \%-93.9 \%) ; 27$ (42.9\%) patients were in stages 1-2 and had a 36 -month OS of $40.8 \%(95 \% \mathrm{CI}=22.7 \%-73.1 \%$; $\mathrm{p}=0.004)$. Fortythree $(\mathrm{n}=43,68.3 \%)$ patients were in TNM stage I with a 36-month OS of $66.6 \%(95 \% \mathrm{CI}=50.2 \%-88.4 \%) ; 20(31.7 \%)$ patients were in TNM stage II and presented a 36 -month OS of $43.2 \%$ (95\%CI $=23.6 \%-78.9 \%$; $\mathrm{p}=0.035$ ). Compared to the other staging systems (BCLC, CLIP and $\mathrm{TNM}^{7 \text { th }}$; Table 3), CLIP had the lower p-value.

\section{Refinement of current clinical staging systems}

Patients were restaged to determine whether our combined clinical and molecular model predicting recurrence could further stratify the different categories of CLIP, BCLC and AJCC/TNM (Table 4 and Figure 4). Among patients in BCLC 0-A, 42 (91.3\%) were in the low risk class according to our clinical and molecular model with a 36-month OS of $70.0 \%$ (95\%CI $=53.2 \%-92.1 \%)$ and $4(8.7 \%)$ patients were in the high risk class with a 36 -month OS rate of $50.0 \%(95 \% \mathrm{CI}=18.8 \%$ $100.0 \% ; \mathrm{p}=0.05)$. In BCLC B, $9(52.9 \%)$ patients were in the low risk while 8 (47.1\%) in high risk classes; the 36-month OS resulted $71.1 \%$ $(95 \% \mathrm{CI}=43.3 \%-100.0 \%)$ and $12.5 \%(95 \% \mathrm{CI}=2.0 \%-78.2 \% ; \mathrm{p}=0.036)$, respectively.

In CLIP 0 , all the 36 patients were in the low risk class; by contrast, in CLIP 1-2, 15 (55.6\%) patients were in the low risk class, and 12

\begin{tabular}{|c|c|c|c|c|c|}
\hline & N (\%) & $\begin{array}{c}\text { OS }(95 \% \mathrm{Cl}) \text { at } 36 \\
\text { months }\end{array}$ & $p^{a}$ & $\begin{array}{c}\text { HR }(95 \% \\
\mathrm{Cl})\end{array}$ & $p^{b}$ \\
\hline $\begin{array}{c}\text { Gender } \\
\mathrm{M} \\
\mathrm{F}\end{array}$ & $\begin{array}{l}48(76.2 \%) \\
15(23.8 \%)\end{array}$ & $\begin{array}{l}60.9 \%(42.2 \%-79.6 \%) \\
56.5 \%(23.1 \%-89.9 \%)\end{array}$ & 0.999 & & \\
\hline $\begin{array}{l}\text { Age } \\
\leq 70 \\
>70\end{array}$ & $\begin{array}{l}35(55.6 \%) \\
28(44.5 \%)\end{array}$ & $\begin{array}{l}67.5 \%(47.6 \%-87.4 \%) \\
50.2 \%(24.0 \%-76.3 \%)\end{array}$ & 0.572 & & \\
\hline $\begin{array}{l}\text { Nodule } \\
\text { Single } \\
\text { Multifocal }\end{array}$ & $\begin{array}{l}43(68.3 \%) \\
20(31.7 \%)\end{array}$ & $\begin{array}{l}66.6 \%(50.2 \%-88.4 \%) \\
43.2 \%(23.6 \%-78.9 \%)\end{array}$ & 0.035 & & \\
\hline $\begin{array}{l}\text { Size } \\
\leq 3 \mathrm{~cm} \\
>3 \mathrm{~cm}\end{array}$ & $\begin{array}{l}19(30.2 \%) \\
44(69.8 \%)\end{array}$ & $\begin{array}{l}67.0 \%(36.1 \%-97.9 \%) \\
56.4 \%(36.9 \%-75.9 \%)\end{array}$ & 0.158 & & \\
\hline $\begin{array}{c}\text { AFP } \\
\leq 400 \mathrm{ng} / \mathrm{mL} \\
>400 \mathrm{ng} / \mathrm{mL}\end{array}$ & $\begin{array}{l}51(81.0 \%) \\
12(19.0 \%)\end{array}$ & $\begin{array}{c}68.1 \%(53.5 \%-86.6 \%) \\
33.3 \%(11.6-96.1 \%)\end{array}$ & 0.003 & & \\
\hline $\begin{array}{l}\text { Albumin } \\
\leq 35 \mathrm{~g} / \mathrm{L} \\
>35 \mathrm{~g} / \mathrm{L}\end{array}$ & $\begin{array}{c}5(12.7 \%) \\
58(87.3 \%)\end{array}$ & $\begin{array}{c}64.1 \%(46.7 \%-81.5 \%) \\
40.0 \%(0.0 \%-85.4 \%)\end{array}$ & 0.010 & & \\
\hline $\begin{array}{c}\quad \mathrm{PT} \\
\leq 1.1 \mathrm{INR} \\
>1.1 \mathrm{INR}\end{array}$ & $\begin{array}{l}43(68.3 \%) \\
20(31.7 \%)\end{array}$ & $\begin{array}{c}75.6 \%(59.6 \%-91.6 \%) \\
30.0 \%(0.0 \%-63.6 \%)\end{array}$ & 0.010 & & \\
\hline $\begin{array}{l}\text { Bilirubin } \\
\leq 2 \mathrm{mg} / \mathrm{mL} \\
>2 \mathrm{mg} / \mathrm{mL}\end{array}$ & $\begin{array}{c}59(93.7 \%) \\
4(6.3 \%)\end{array}$ & $\begin{array}{c}59.7 \%(42.3 \%-77.1 \%) \\
0.0 \%(\mathrm{NA})\end{array}$ & 0.284 & & \\
\hline $\begin{array}{c}\text { Platelets } \\
\leq 150000 / \mathrm{mm}^{3} \\
>150000 / \mathrm{mm}^{3}\end{array}$ & $\begin{array}{l}22(34.9 \%) \\
41(65.1 \%)\end{array}$ & $\begin{array}{l}63.0 \%(33.1 \%-92.8 \%) \\
63.0 \%(44.7 \%-81.3 \%)\end{array}$ & 0.655 & & \\
\hline $\begin{array}{c}\text { MYC status } \\
\text { Disomic } \\
\text { Polysomic } \\
\text { Amplified }\end{array}$ & $\begin{array}{l}17(26.9 \%) \\
34(53.9 \%) \\
12(19.2 \%)\end{array}$ & $\begin{array}{l}61.6 \%(38.7 \%-98.2 \%) \\
50.4 \%(26.0 \%-97.5 \%) \\
35.7 \%(15.5 \%-82.4 \%)\end{array}$ & 0.05 & & \\
\hline $\begin{array}{c}\text { Class of risk } \\
\text { Low risk } \\
\text { High risk }\end{array}$ & $\begin{array}{l}51(80.9 \%) \\
12(19.1 \%)\end{array}$ & $\begin{array}{c}70.0 \%(54.8 \%-89.6 \%) \\
15.0 \%(2.8 \%-78.8 \%)\end{array}$ & $<0.001$ & $\begin{array}{c}\text { reference } \\
6.82(2.72 \\
-17.08)\end{array}$ & $<0.001$ \\
\hline
\end{tabular}

a $\mathrm{p}$-values were obtained using the log-rank test for Kaplan-Meier survival curves. ${ }^{\mathrm{b}} \mathrm{p}$-values were obtained using the multivariate Cox proportional hazard regression model.

Table 2: Univariate and multivariate analysis for OS of 63 patients with HCC. 
Citation: Ruzzenente A, Bagante F, Sandri BSM, Pedrazzani C, Brunelli M, et al. (2016) Risk A Novel Prognostic Score based on Serum AlphaFetoprotein, Number of Nodules, and MYC Gene Status Predicts Prognosis of Patients after Liver Resection for Hepatocellular Carcinoma. J Integr Oncol 5: 168. doi:10.4172/2329-6771.1000168

Page 5 of 9

\begin{tabular}{|c|c|c|c|c|}
\hline & $\mathrm{N}^{\circ}$ of patients (\%) & $\mathrm{N}^{\circ}$ of events in the class $(\%)^{a}$ & OS $(95 \% \mathrm{Cl})$ at 36 months & $p^{b}$ \\
\hline $\begin{array}{c}\text { Class of risk } \\
\text { Low } \\
\text { High }\end{array}$ & $\begin{array}{l}51(80.9 \%) \\
12(19.1 \%)\end{array}$ & $\begin{array}{l}11(21.6 \%) \\
9(75.0 \%)\end{array}$ & $\begin{array}{c}70.0 \%(54.8 \%-89.6 \%) \\
15.0 \%(2.8 \%-78.8 \%)\end{array}$ & $<0.001$ \\
\hline $\begin{array}{c}\text { BCLC } \\
0-A \\
B\end{array}$ & $\begin{array}{l}46(73.1 \%) \\
17(26.9 \%)\end{array}$ & $\begin{array}{l}11(23.9 \%) \\
9(52.9 \%)\end{array}$ & $\begin{array}{l}67.4 \%(51.1 \%-89.1 \%) \\
37.2 \%(18.2 \%-75.8 \%)\end{array}$ & 0.010 \\
\hline $\begin{array}{c}\text { CLIP } \\
0\end{array}$ & $36(57.1 \%)$ & $8(22.2 \%)$ & $71.6 \%(54.6 \%-93.9 \%)$ & 0.004 \\
\hline $1-2$ & $27(42.9 \%)$ & $12(44.4 \%)$ & $40.8 \%(22.7 \%-73.1 \%)$ & \\
\hline $\begin{array}{l}\text { TNM } 7^{\text {th }} \\
\text { stage I }\end{array}$ & $43(68.3 \%)$ & $11(25.6 \%)$ & $66.6 \%(50.2 \%-88.4 \%)$ & 0.035 \\
\hline stage II & $20(31.7 \%)$ & $9(45.0 \%)$ & $43.2 \%(23.6 \%-78.9 \%)$ & \\
\hline
\end{tabular}

apercentage referees to patients at risk in the class.

${ }^{b} p$-values were obtained using the log-rank test for Kaplan-Meier survival curves.

Table 3: Classification and OS (at 36 months) of patients according to our novel clinical and molecular classification, BCLC, CLIP and TNM $7^{\text {th }}$.

a)
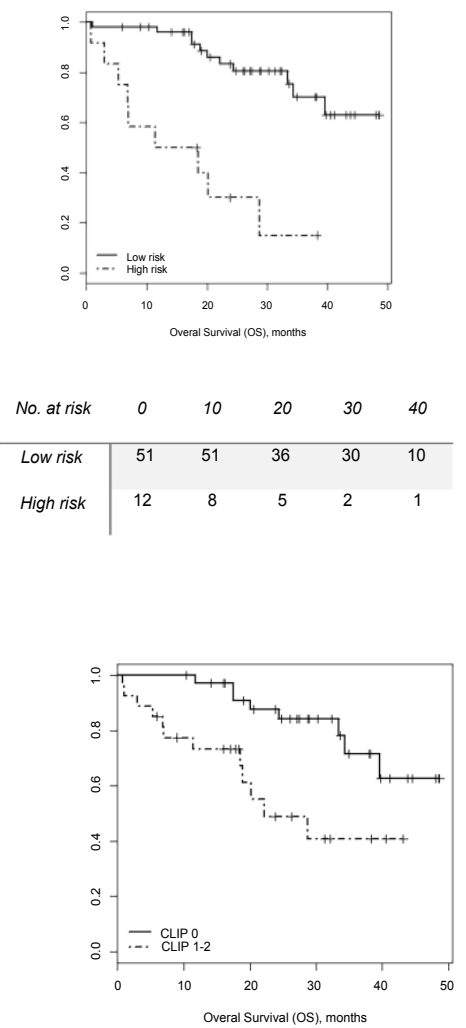

\begin{tabular}{c|ccccc} 
No. at risk & 0 & 10 & 20 & 30 & 40 \\
\hline CLIP 0 & 36 & 36 & 30 & 25 & 7 \\
CLIP 1-2 & 27 & 21 & 11 & 6 & 5
\end{tabular}

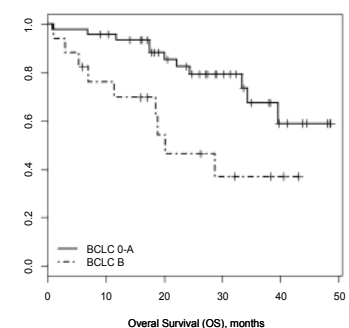

\begin{tabular}{c|ccccc} 
No. at risk & 0 & 10 & 20 & 30 & 40 \\
\hline BCLC O-A & 46 & 45 & 35 & 26 & 8 \\
BCLC B & 17 & 13 & 8 & 5 & 4
\end{tabular}

d)

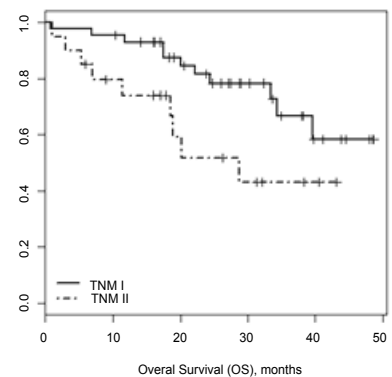

\begin{tabular}{c|ccccc} 
No. at risk & 0 & 10 & 20 & 30 & 40 \\
\hline TNM I & 43 & 42 & 33 & 25 & 8 \\
TNM II & 20 & 16 & 9 & 6 & 5
\end{tabular}

Figure 3: Overall survival curves estimated by Kaplan-Meier method stratified by (a) our classification, (b) BCLC, (c) CLIP and (d) TNM $7^{\text {th }}$.

(44.4\%) were in high risk class; 36 -month OS was 66.7 (95\% CI $=40.9 \%$ $100.0 \%)$ and $15.0 \%(95 \% \mathrm{CI}=2.9 \%-78.8 ; \mathrm{p}=0.01)$, respectively.

Thirty-nine $(\mathrm{n}=39,90.7 \%)$ patients in TNM stage I were in the low risk class and $4(9.3 \%)$ in the high risk class; OS rate at 36 months was $69.4 \%(95 \% \mathrm{CI}=52.5-91.6 \%)$ and $50.0 \%(95 \% \mathrm{CI}=18.8 \%$ 100.0\%; $\mathrm{p}=0.06)$, respectively. In TNM stage II, 12 (60.0\%) patients were in the low risk class and presented an OS at 36 months of $76.4 \%$ (95\% CI $=51.4 \%-100.0 \%)$, while 8 (40.0\%) patients were in the high risk class and reached an OS rate at 36 months of $12.5 \%$ (95\% CI $=2.0 \%$ $78.2 \%$; $=0.009$ ).

Moreover, we calculated the discriminative ability for OS of our prognostic model, of the three staging systems (BCLC, CLIP and 
Citation: Ruzzenente A, Bagante F, Sandri BSM, Pedrazzani C, Brunelli M, et al. (2016) Risk A Novel Prognostic Score based on Serum AlphaFetoprotein, Number of Nodules, and MYC Gene Status Predicts Prognosis of Patients after Liver Resection for Hepatocellular Carcinoma. J Integr Oncol 5: 168. doi:10.4172/2329-6771.1000168

Page 6 of 9

\begin{tabular}{|c|c|c|c|c|}
\hline & $\mathbf{N}^{\circ}$ of patients & $\mathbf{N}^{\circ}$ of events in the class ${ }^{a}$ & OS $(95 \% \mathrm{Cl})$ at 36 months & $p^{b}$ \\
\hline $\begin{array}{l}\text { BCLC 0-A } \\
\text { Low risk class } \\
\text { High risk class }\end{array}$ & $\begin{array}{c}42(91.3 \%) \\
4(8.7 \%)\end{array}$ & $\begin{array}{l}9(21.4 \%) \\
2(50.0 \%)\end{array}$ & $\begin{array}{c}70.0 \%(53.2 \%-92.1 \%) \\
50.0 \%(18.8 \%-100.0 \%)\end{array}$ & 0.050 \\
\hline $\begin{array}{c}\text { BCLC B } \\
\text { Low risk class } \\
\text { High risk class }\end{array}$ & $\begin{array}{l}9(52.9 \%) \\
8(47.1 \%)\end{array}$ & $\begin{array}{l}2(22.2 \%) \\
7(87.5 \%)\end{array}$ & $\begin{array}{l}71.1 \%(43.3 \%-100 \%) \\
12.5 \%(2.0 \%-78.2 \%)\end{array}$ & 0.036 \\
\hline $\begin{array}{c}\text { CLIP } 0 \\
\text { Low risk class } \\
\text { High risk class }\end{array}$ & $\begin{array}{c}36(100.0 \%) \\
0(0.0 \%)\end{array}$ & $\begin{array}{c}8(22.2 \%) \\
-\end{array}$ & $\begin{array}{c}71.6 \%(54.6 \%-93.9 \%) \\
-\end{array}$ & - \\
\hline $\begin{array}{l}\text { CLIP 1-2 } \\
\text { Low risk class } \\
\text { High risk class }\end{array}$ & $\begin{array}{l}15(55.6 \%) \\
12(44.4 \%)\end{array}$ & $\begin{array}{l}3(20.0 \%) \\
9(75.0 \%)\end{array}$ & $\begin{array}{l}66.7 \%(40.9 \%-100 \%) \\
15.0 \%(2.8 \%-78.8 \%)\end{array}$ & 0.012 \\
\hline $\begin{array}{l}\text { TNM } 7^{\text {th }} \text { stage I } \\
\text { Low risk class } \\
\text { High risk class }\end{array}$ & $\begin{array}{c}39(90.7 \%) \\
4(9.3 \%)\end{array}$ & $\begin{array}{l}9(23.1 \%) \\
2(50.0 \%)\end{array}$ & $\begin{array}{l}69.4 \%(52.5 \%-91.6 \%) \\
50.0 \%(18.8 \%-100 \%)\end{array}$ & 0.060 \\
\hline $\begin{array}{r}\text { TNM } 7^{\text {th }} \text { stage II } \\
\text { Low risk class } \\
\text { High risk class }\end{array}$ & $\begin{array}{l}12(60.0 \%) \\
8(40.0 \%)\end{array}$ & $\begin{array}{l}2(16.7 \%) \\
7(87.5 \%)\end{array}$ & $\begin{array}{c}76.4 \%(51.4 \%-100 \%) \\
12.5 \%(2.0 \%-78.2 \%)\end{array}$ & 0.009 \\
\hline
\end{tabular}

apercentage referees to patients at risk in the class.

${ }^{b} p$-value was obtained using the exact log-rank test for Kaplan-Meier survival curves.

Table 4: Reclassification with our clinical and molecular model of patients staged with BCLC, CLIP and TNM $7^{\text {th }}$.

a)

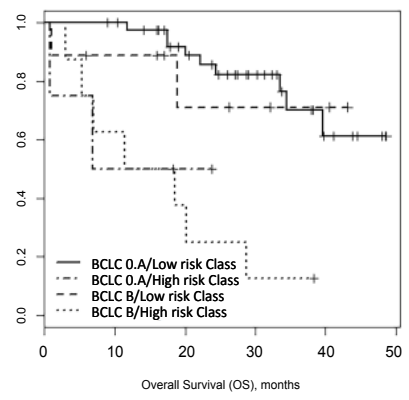

\begin{tabular}{c|ccccc} 
No. at risk & 0 & 10 & 20 & 30 & 40 \\
\hline BCLC 0-A/Low risk & 42 & 42 & 30 & 26 & 8 \\
BCLC 0-A/High risk & 4 & 2 & - & - & - \\
BCLC B/Low risk & 9 & 9 & 4 & - & - \\
BCLC B/High risk & 8 & 5 & 3 & 1 & -
\end{tabular}

C)

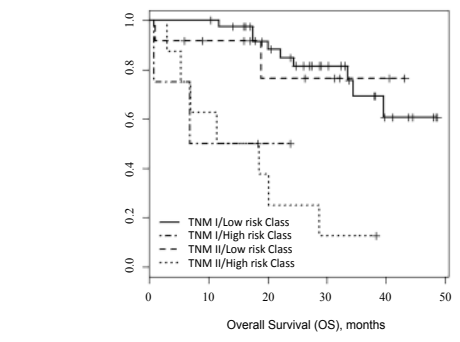

b)

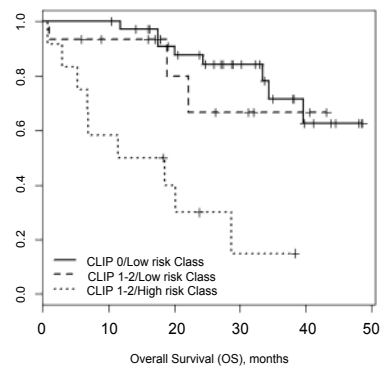

$\begin{array}{llllll}\text { No. at risk } & 0 & 10 & 20 & 30 & 40\end{array}$

\begin{tabular}{c|ccccc}
\hline CLIP 0/Low risk & 36 & 36 & 28 & 25 & 8 \\
CLIP 1-2/Low risk & 15 & 15 & 7 & 6 & - \\
CLIP 1-2/High risk & 12 & 8 & 5 & - & -
\end{tabular}

\begin{tabular}{c|rrrrc} 
No. at risk & 0 & 10 & 20 & 30 & 40 \\
\hline TNM I/Low risk & 39 & 39 & 29 & 25 & 7 \\
TNK I/High risk & 4 & 2 & - & - & - \\
TNM II/Low risk & 12 & 12 & 6 & - & -
\end{tabular}

Figure 4: Overall survival curves estimated by Kaplan-Meier method, integrating our model with (a) BCLC, (b) CLIP and (c) TNM $7^{\text {th }}$. 
Citation: Ruzzenente A, Bagante F, Sandri BSM, Pedrazzani C, Brunelli M, et al. (2016) Risk A Novel Prognostic Score based on Serum AlphaFetoprotein, Number of Nodules, and MYC Gene Status Predicts Prognosis of Patients after Liver Resection for Hepatocellular Carcinoma. J Integr Oncol 5: 168. doi:10.4172/2329-6771.1000168

AJCC/TNM $7^{\text {th }}$ ed.) and of the same staging systems incorporating our novel clinical and molecular model (Table 5).

CLIP reclassified with our novel clinical and molecular model presented the most predictive power compared with others staging systems (BCLC, CLIP, AJCC/TNM $7^{\text {th }}$ ed., BCLC reclassified and TNM reclassified; (Table 5); the c-index for CLIP reclassified was $73.4 \%$ when corrected with cross-validation and bootstrapping resampling $(\mathrm{n}=$ 5000) to avoid optimistic assessment (Table 5).

\section{Discussion}

Classifying patients into prognostic groups is important for the clinical management of HCC [31]. Currently, the clinical staging systems include variables associated with tumor features (e.g., tumor size, number of tumor nodules, vascular invasion, and distant metastasis) and the severity of liver damage (e.g., protein synthesis and detoxification functions, and symptoms of liver decompensation), [32]. Moreover, among the different clinical classifications, BCLC has endorsed as guideline for the clinical management of HCC patients by both EASL and AASLD [38]. Recent surgical series reported that liver resection should be offered to patients beyond the limitations defined by BCLC [39], and many papers aimed to improve BCLC by using a tailored approach for the treatment of HCC [40,41]. Furthermore, after molecular targeted therapies were proved to be effective in HCC [42], different studies have broadly investigated the genetic background of HCC $[26,43-45]$ to improve the clinical management of this chemoresistant tumor.

However, none of the several clinical staging systems proposed for HCC included molecular parameters from genetic studies that identified molecular classifications for this malignancy [46]. Genomewide [44] techniques should provide an estimation of early and longterm outcomes more accurately than clinical staging systems, but such genetic techniques have not found a clear application in a routine clinical setting [26,27,43,45,47].

Recently, Hoshida et al. proposed a molecular classification of HCC based on gene signatures. The analysis of 603 patients indicated that there are three major subclasses of HCC, which the authors defined subclasses S1, S2, and S3. HCCs in class S2, characterized by a poor prognosis, presented several MYC target genes, suggesting that MYC activation is a feature of S2 HCC [48]. Unfortunately, this molecular classification failed to provide useful information in clinical practice [27].

Among the different molecular markers, MYC deregulation has been implicated in several tumor pathways $[14,49]$, and we recently identified the role of MYC deregulation in survival and recurrence in HCC [24].

In this study, we proposed a novel clinical and molecular model to predict DFS. We combined in a model, HCC biological characteristic

\begin{tabular}{|c|c|c|}
\hline & c-index & Somers' Dxy \\
\hline Class model & $70.8 \%$ & 0.416 \\
\hline BCLC & $64.6 \%$ & 0.293 \\
\hline CLIP & $68.4 \%$ & 0.369 \\
\hline TNM $7^{\text {th }}$ & $65.6 \%$ & 0.313 \\
\hline re-classified BCLC & $71.4 \%$ & 0.428 \\
\hline re-classified CLIP & $73.4 \%$ & 0.469 \\
\hline re-classified TNM $7^{\text {th }}$ & $69.8 \%$ & 0.397 \\
\hline
\end{tabular}

Table 5: Comparison between discriminative ability of staging systems with concordance of prediction expressed by c-index (in \%) and Somers' Dxy.
(MYC status determined by FISH method) and clinical features (number of HCC and serum AFP levels) to predict early recurrence (before or at 12 months) in patients who underwent curative resection for HCC. We developed our model using both continuous score (punctual risk of recurrence) and discrete classification (high or low risk of recurrence). Our discrete classification demonstrated a clear ability to predict the risk of recurrence: in the high risk class, more than $90 \%$ of patients experienced a relapse with a DFS at 36 months of $0 \%$.

Although recurrence is an important end-point for HCC, we investigated the role of our clinical and molecular model regarding OS. Indeed, we observed that patients in high risk class had a very poor prognosis, with an OS at 36 months of $15 \%$; in comparison, patients in low risk class had an OS at 36 months of $70.0 \%(p<0.001)$. Furthermore, we integrated BCLC, CLIP and AJCC/TNM 7th ed. with our clinical and molecular model. Patients classified in the high or low risk classes presented a significant difference in terms of OS within specific classes of risk for BCLC and CLIP. Of note, patients in BCLC 0-A and low risk classes presented a similar OS at 36 months to patients in BCLC B and low risk class: $70 \%$ and $71.1 \%$, respectively. Likewise, patients in the CLIP 0 and low risk classes reached OS comparable to patients in the CLIP 1-2 and low risk class.

To ensure a reliable comparison between staging systems, we used the c-index, a measure of discriminative ability ranging from $50 \%$ (model predictions no better than chance) to $100 \%$ (perfect prediction). Our clinical and molecular model showed a good ability to predict prognosis, with a c-index of $70.8 \%$, but we are aware of the risk of bias with internal validation. When we compared clinical staging systems using different versions of the BCLC, CLIP and AJCC/TNM $7^{\text {th }}$ ed. containing our clinical and molecular model, CLIP combined with our model showed the best ability to predict survival, as evidenced by a c-index of $73.4 \%$.

This study presents several limitations mainly due to the number of patients in subgroups resulting low and their limited follow-up. Despite these limitations, significant differences between patients at low and high risk were detected in nearly all subgroups. Nevertheless, we believe that our findings should be confirmed performing an external validation of our model on a larger clinical series of patients with a prolonged follow-up.

We consider these results a preliminary clinical evidence of the effectiveness of our novel clinical and molecular model. Our model could provide a better stratification and support physician in the decision-making to select patient candidates for surgical resection. In this setting it would be useful for a correct allocation of patients to appropriate treatment. Importantly, all the variables included in our model could be obtained before surgery since the mutational status of MYC could be evaluated with needle biopsy of the tumor before surgery.

\section{Conclusions}

Number of HCC, serum AFP level and MYC status resulted strong predictors of DFS. We propose a novel clinical and molecular model for DFS in patients with HCC who have undergone curative resection based on MYC gene status and HCC clinical features (the number of nodules and the serum AFP level). A graphical representation of our model, a nomogram, was created to simplify the clinical use of our prognostic model. A binary classification (low and high risk of recurrence) based on our model showed a good ability to predict early recurrence. Our model proved its prognostic value in predicting OS in univariate and 
Citation: Ruzzenente A, Bagante F, Sandri BSM, Pedrazzani C, Brunelli M, et al. (2016) Risk A Novel Prognostic Score based on Serum AlphaFetoprotein, Number of Nodules, and MYC Gene Status Predicts Prognosis of Patients after Liver Resection for Hepatocellular Carcinoma. J Integr Oncol 5: 168. doi:10.4172/2329-6771.1000168

multivariable analysis. Moreover, our model, when added to clinical staging systems (BCLC, CLIP and AJCC/TNM $7^{\text {th }}$ ed.), significantly refined the classification of patients with HCC. The information of the proposed novel clinical and molecular model could be support to clinicians to address patients to the most appropriate surgical therapy (resection and transplantation) or to other non-surgical therapies since the mutational status of MYC could be evaluated with needle biopsy of the tumor before surgery.

\section{Funding}

Associazioni Italiana Ricerca Cancro (AIRC) grants $\mathrm{n}^{\circ} 12182$ and 6421; Italian Cancer Genome Project (FIRB RBAP10AHJB to AS); Cam-Pac FP7 Grant agreement n602783.

\section{References}

1. El-Serag HB, Rudolph KL (2007) Hepatocellular carcinoma: epidemiology and molecular carcinogenesis. Gastroenterology 132: 2557-2576.

2. Schütte K, Bornschein J, Malfertheiner $P$ (2009) Hepatocellular carcinoma-epidemiological trends and risk factors. Dig Dis 27: 80-92.

3. Bruix J, Sherman M; American Association for the Study of Liver Diseases (2011) Management of hepatocellular carcinoma: an update. Hepatology 53: 1020-1022.

4. European Association For The Study Of The L, European Organisation For R, Treatment Of C (2012) EASL-EORTC Clinical Practice Guidelines: Management of hepatocellular carcinoma. Journal of hepatology 56: 908-943.

5. Edge SB, Compton CC (2010) The American Joint Committee on Cancer: the 7 th edition of the AJCC cancer staging manual and the future of TNM. Ann Surg Oncol 17: 1471-1474

6. A new prognostic system for hepatocellular carcinoma: a retrospective study of 435 patients: the Cancer of the Liver Italian Program (CLIP) investigators. Hepatology 28: 751-755.

7. Guglielmi A, Ruzzenente A, Pachera S, Valdegamberi A, Sandri M, et al. (2008) Comparison of seven staging systems in cirrhotic patients with hepatocellular carcinoma in a cohort of patients who underwent radiofrequency ablation with complete response. The American journal of gastroenterology 103: 597-604.

8. Huang J, Zhang Y, Peng Z, Gao H, Xu L, et al. (2013) A modified TNM-7 staging system to better predict the survival in patients with hepatocellular carcinoma after hepatectomy. J Cancer Res Clin Oncol 139: 1709-1719.

9. Chan AC, Poon RT, Cheung TT, Chok KS, Chan SC, et al. (2012) Survival analysis of re-resection versus radiofrequency ablation for intrahepatic recurrence after hepatectomy for hepatocellular carcinoma. World J Surg 36: $151-156$

10. Poon RT, Fan ST, Ng IO, Wong J (2000) Significance of resection margin in hepatectomy for hepatocellular carcinoma: A critical reappraisal. Ann Surg 231: 544-551.

11. Dang CV, O'Donnell KA, Zeller KI, Nguyen T, Osthus RC, et al. (2006) The c-Myc target gene network. Semin Cancer Biol 16: 253-264.

12. Schlaeger C, Longerich T, Schiller C, Bewerunge P, Mehrabi A, et al. (2008) Etiology-dependent molecular mechanisms in human hepatocarcinogenesis. Hepatology 47: 511-520.

13. Buendia MA, Bourre L, Cairo S (2012) Myc target miRs and liver cancer: small molecules to get Myc sick. Gastroenterology 142: 214-218.

14. Fernandez PC, Frank SR, Wang L, Schroeder M, Liu S, et al. (2003) Genomic targets of the human c-Myc protein. Genes Dev 17: 1115-1129.

15. Cawley S, Bekiranov S, Ng HH, Kapranov P, Sekinger EA, et al. (2004) Unbiased mapping of transcription factor binding sites along human chromosomes 21 and 22 points to widespread regulation of noncoding RNAs. Cell 116: 499-509.

16. Li Z, Van Calcar S, Qu C, Cavenee WK, Zhang MQ, et al. (2003) A global transcriptional regulatory role for c-Myc in Burkitt's lymphoma cells. Proc Natl Acad Sci U S A 100: 8164-8169.

17. Baudino TA, McKay C, Pendeville-Samain H, Nilsson JA, Maclean KH, et al. (2002) c-Myc is essential for vasculogenesis and angiogenesis during development and tumor progression. Genes Dev 16: 2530-2543.
18. Brunelli M, Manfrin E, Martignoni G, Bersani S, Remo A, et al. (2008) HER-2 neu assessment in breast cancer using the original FDA and new ASCO/CAP guideline recommendations: impact on selecting patients for herceptin therapy. American journal of clinical pathology 129: 907-911.

19. Brunelli M, Manfrin E, Martignoni G, Miller K, Remo A, et al. (2009) Genotypic intratumoral heterogeneity in breast carcinoma with HER2/neu amplification evaluation according to ASCO/CAP criteria. American journal of clinical pathology 131: 678-682.

20. Laurent A, Patrick A, Jerome C, Marion GM, Catherine L, et al. (2007) Pathologic complete response to trastuzumab-based neoadjuvant therapy is related to the level of HER-2 amplification. Clinical cancer research : an official journal of the American Association for Cancer Research 13: 6404-6409

21. Moelans CB, de Weger RA, Monsuur HN, Vijzelaar R, van Diest PJ (2010) Molecular profiling of invasive breast cancer by multiplex ligation-dependent probe amplification-based copy number analysis of tumor suppressor and oncogenes. Mod Pathol 23: 1029-1039.

22. Zhang QL, Luo CL, Wu XH, Wang CY, Xu X, et al. (2011) HepaCAM induces G1 phase arrest and promotes c-Myc degradation in human renal cell carcinoma J Cell Biochem 112: 2910-2919.

23. Tang SW, Chang WH, Su YC, Chen YC, Lai YH, et al. (2009) MYC pathway is activated in clear cell renal cell carcinoma and essential for proliferation of clear cell renal cell carcinoma cells. Cancer Lett 273: 35-43.

24. Pedica F, Ruzzenente A, Bagante F, Capelli P, Cataldo I, et al. (2013) A reemerging marker for prognosis in hepatocellular carcinoma: the add-value of fishing c-myc gene for early relapse. PLoS One 8: e68203.

25. Forner A, Llovet JM, Bruix J (2012) Hepatocellular carcinoma. Lancet 379: 1245-1255.

26. Hoshida Y, Villanueva A, Kobayashi M, Peix J, Chiang DY, et al. (2008) Gene expression in fixed tissues and outcome in hepatocellular carcinoma. $\mathrm{N}$ Eng J Med 359: 1995-2004.

27. Villanueva A, Hoshida Y, Battiston C, Tovar V, Sia D, et al. (2011) Combining clinical, pathology, and gene expression data to predict recurrence of hepatocellular carcinoma. Gastroenterology 140: 1501-1512.

28. Belghiti J, Kianmanesh R (2005) Surgical treatment of hepatocellular carcinoma. HPB (Oxford) 7: 42-49.

29. Edmondson HA, Steiner PE (1954) Primary carcinoma of the liver: a study of 100 cases among 48,900 necropsies. Cancer 7: 462-503.

30. von Elm E, Altman DG, Egger M, Pocock SJ, Gotzsche PC, et al. (2007) The Strengthening the Reporting of Observational Studies in Epidemiology (STROBE) statement: guidelines for reporting observational studies. Lancet 370: 1453-1457.

31. Llovet JM, Burroughs A, Bruix J (2003) Hepatocellular carcinoma. Lancet 362 1907-1917.

32. Tandon P, Garcia-Tsao G (2009) Prognostic indicators in hepatocellular carcinoma: a systematic review of 72 studies. Liver international: official journal of the International Association for the Study of the Liver 29: 502-510.

33. Pencina MJ, D'Agostino RB (2004) Overall C as a measure of discrimination in survival analysis: model specific population value and confidence interval estimation. Statistics in medicine 23: 2109-2123.

34. Dean CB, Nielsen JD (2007) Generalized linear mixed models: a review and some extensions. Lifetime Data Anal 13: 497-512.

35. Therneau T (2013) A Package for Survival Analysis in S. R package.

36. Therneau T (2013) rms: Regression Modeling Strategies. R package.

37. Hothorn T, Hornik K, Van de Wiel MA, Zeileis A (2006) A Lego system for conditional inference. Am Stat 60: 257-263.

38. Llovet JM, Brú C, Bruix J (1999) Prognosis of hepatocellular carcinoma: the BCLC staging classification. Semin Liver Dis 19: 329-338.

39. Majno PE, Mentha G, Mazzaferro V (2010) Partial hepatectomy versus radiofrequency ablation for hepatocellular carcinoma: confirming the tria that will never be, and some comments on the indications for liver resection. Hepatology 51: 1116-1118

40. Hsu C, Po Ching L, Morita S, Hu FC, Cheng AL (2012) Perspectives on the Design of Clinical Trials Combining Transarterial Chemoembolization and Molecular Targeted Therapy. Liver cancer 1: 168-176. 
Citation: Ruzzenente A, Bagante F, Sandri BSM, Pedrazzani C, Brunelli M, et al. (2016) Risk A Novel Prognostic Score based on Serum AlphaFetoprotein, Number of Nodules, and MYC Gene Status Predicts Prognosis of Patients after Liver Resection for Hepatocellular Carcinoma. J Integr Oncol 5: 168. doi:10.4172/2329-6771.1000168

41. Yang JD, Kim WR, Park KW, Chaiteerakij R, Kim B, et al. (2012) Model to estimate survival in ambulatory patients with hepatocellular carcinoma. Hepatology 56: 614-621.

42. Bruix J, Gores GJ, Mazzaferro V (2014) Hepatocellular carcinoma: clinical frontiers and perspectives. Gut 63: 844-855.

43. Chiang DY, Villanueva A, Hoshida Y, Peix J, Newell P, et al. (2008) Focal gains of VEGFA and molecular classification of hepatocellular carcinoma. Cancer Res 68: 6779-6788.

44. Hoshida Y, Toffanin S, Lachenmayer A, Villanueva A, Minguez B, et al. (2010) Molecular classification and novel targets in hepatocellular carcinoma: recent advancements. Semin Liver Dis 30: 35-51.

45. Boyault S, Rickman DS, de Reyniès A, Balabaud C, Rebouissou S, et al.
(2007) Transcriptome classification of HCC is related to gene alterations and to new therapeutic targets. Hepatology 45: 42-52.

46. Mínguez B, Lachenmayer A (2011) Diagnostic and prognostic molecula markers in hepatocellular carcinoma. Dis Markers 31: 181-190.

47. Yamashita T, Forgues M, Wang W, Kim JW, Ye Q, et al. (2008) EpCAM and alpha-fetoprotein expression defines novel prognostic subtypes of hepatocellular carcinoma. Cancer research 68: 1451-1461.

48. Hoshida Y, Nijman SM, Kobayashi M, Chan JA, Brunet JP, et al. (2009) Integrative transcriptome analysis reveals common molecular subclasses of human hepatocellular carcinoma. Cancer research 69: 7385-7392.

49. Dang CV (1999) c-Myc target genes involved in cell growth, apoptosis, and metabolism. Mol Cell Biol 19: 1-11. 